\title{
Structural synthesis of electrical engineering complex' control system of a plant for plastic shaping of the ceramic mixture
}

\author{
Stanislav Galitskov ${ }^{1}$, Maxim Nazarov ${ }^{1 *}$, and Konstantin Galitskov ${ }^{1}$ \\ ${ }^{1}$ Samara State Technical University, Institute of Architecture and Civil Engineering, \\ 194, Molodogvardeyskaya St., 443001, Samara, Russia
}

\begin{abstract}
Production of ceramic bricks with the required strength imposes significant restrictions on the process control of plastic shaping of the ceramic mixture in the auger extruder. It is due to several factors. Firstly, the certain nonstationarity of rheological properties of the source raw materials necessitates the automatic task-oriented changes in combinations of such values as shear rate, ceramic mixture moisture and vacuum pressure in the vacuum chamber of the extruder. To solve this problem it is necessary to maintain a coordinated control of the relevant automatic control systems of the electrical engineering complex. The second problem is the lack of technical tools to measure the values of shear rate in the pressure head of the extruder. And finally, the third factor is a necessity for monitoring and modeling of operating steps in brick production - from shaping to finished product output, that is a necessity to assess the impact of drying and firing processes on the possibility to make bricks of specified strength. The paper considers structural synthesis of the electrical engineering complex' control system for plastic shaping of the ceramic mixture, including the problem of coordinated control: of the vacuum pump' electrical drive, of the solenoid valve for water dosing, of the belt feeder' electrical drives, of the mixer and the auger, as well as the use of digital observers of technological controlled coordinates and models in further phases of brick production.
\end{abstract}

\section{Introduction}

When manufacturing bricks, plastic shaping of the ceramic mixture in the auger vacuum extruder has gained widespread [1-5], which is considered, with regard to automation of this process, to be the electrical engineering complex, including electromechanical drives of the auger vacuum extruder (the clay mixer, the vacuum pump and the extruder itself) and the electromagnetic dosing device for regulating moister and temperature of the clay mixture in the mixer [6-8]. The practice of ceramic brick production has proved that strength, structure homogeneity and geometric shape defect strongly depend on

\footnotetext{
*Corresponding author: nazarovm86@yandex.ru
} 
technological parameters of adobe brick shaping, which, in turn, are determined by operational modes of actuating devices [6-9].

Existing control methods of shaping are mainly limited to automatic stabilization of either ceramic mixture pressure in the pressure head, or moister in the clay mixer [10]. In these automated systems the actuating devices are solenoid valves for water and steam dosing. Such limited use of the complex' electrical drives control does not allow achieving stable production of bricks of the required brand in circumstances where one should meet the modern requirements for energy efficiency and plant productivity when original properties of raw materials and technological conditions of production can differ.

The paper deals with modernization of methods and techniques of coordinated control of the complex' electrical drives, which is, in particular, aimed at providing the required strength of manufactured bricks at minimum energy consumption and maximum achievable productivity.

\section{Materials and methods}

The results of the research conducted by Barabanshchikov Yu.G., Tretyakov I.M., Golubovich S.R. $[6,11,12]$ on the influence of the main characteristics of plastic shaping on the strength of the finished brick and occurrence of structure homogeneity defects and geometrical errors assuming the stability of the drying and firing technology, allowed obtaining the three-dimensional space, coordinates of which are technological parameters of shaping - moisture content $w$, vacuum pressure $P_{v}$ in the vacuum chamber and shear rate $\dot{\gamma}$ of the ceramic mixture in the exit section of the pressure head. Part of this space is allocated for the area controlling the electrical engineering complex of the plant for plastic shaping of the ceramic mixture, the analysis of which allows making a conclusion that to ensure stable production of bricks of the required brand at minimum energy consumption and maximum possible productivity under a number of disturbances it is necessary to have coordinated control of electrical engineering complex' drives as a function of shear rate of the ceramic mixture in the pressure head of the auger extruder, which is the main parameter defining the finished brick strength.

\section{Results}

The structural synthesis of the control system of such a compound object as the complex under consideration highlights two problems [6,13-15]: definition of reference signal values, which ensure the production of ceramic bricks of specified strength and robust stability of the system that controls the auger' electrical drive under the conditions of changing parameters of the clay raw materials.

The first problem is solved by using the generator of reference signals vector. These signals are applied at the stage of forming local control systems. The second problem is solved by applying the ACS of the auger' electrical drive in the form of the dual circuit system with one measured coordinate.

The mixer and the belt feeder of existing models of the auger extruders have unregulated drives, so the change in $\dot{\gamma}$ results in discrepancy between productivities of the belt feeder $G_{b f}$, the mixer $G_{m}$, the extruder, and consequently, in changes of the filling levels $h_{v c}$ and $h_{m}$ of the vacuum chamber and the mixer, respectively. This technological unbalance of complex' devices operation causes significant deviation of the shaped brick properties from the required values. Therefore, it is necessary to ensure automatic coordination of the extruder, the mixer and the belt feeder modes. Thus, in addition to the automatic control system of the auger electric drive, the vacuum pump and the solenoid 
valve for water dosing, that determine shear rate $\dot{\gamma}$, vacuum pressure $P_{v}$ and moister $w$, respectively, the system of automatic control of this electrical engineering complex (fig. 1) includes the control system of the belt feeder and clay mixer drives that support filling levels $h_{m}$ of the mixer and $h_{v c}$ of the vacuum chamber.

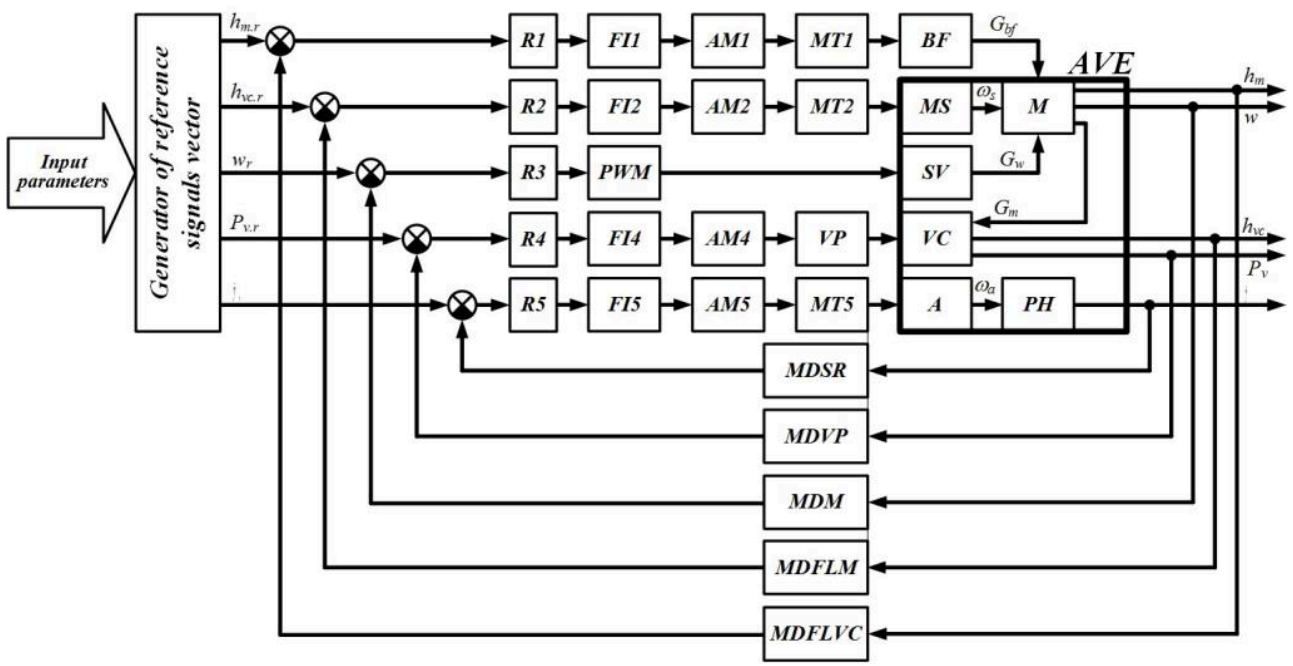

Fig. 1. The structure of the electrical engineering complex' control system of the plant for plastic shaping of the ceramic mixture: R1, R2, R3, R4, R5 - the controllers of the local control systems; FI1, FI2, FI4, FI5 - the variable speed drivers; PWM - the pulse-width modulator; AM1, AM2, AM4, AM5 - the asynchronous motors; MT1, MT2, MT5 - the mechanical transmissions; VP - the vacuum pump; VC - the vacuum chamber; $\mathrm{BF}$ - the belt feeder; MS - the mixer shafts; $\mathrm{M}$ - the mixer; SV the solenoid valve; A - the auger; PH - the pressure head; AVE - the auger vacuum extruder; MDSR, MDM, MDVP, MDFLM, MDFLVC the measuring devices of shear rate and moister of the ceramic mixture, of vacuum pressure in the vacuum chamber, of filling level in the mixer and vacuum chambers, respectively; $\omega_{s}, \omega_{a}$ - angular velocity of shafts rotation of the mixer and the auger, respectively; $G_{w}$ - water flow rate; parameters with the index " $r$ " - reference signals.

Practical implementation of the control system is constrained by inability to measure shear rate $\dot{\gamma}$ in modern conditions. So it is important to develop the device, allowing not only to indirectly calculate the value $\dot{\gamma}$, but also to determine (based on the target strength values $R_{r}$ of brick, constraints on the mixture technological characteristics, constraints conditioned by the technical characteristics of the extruder) the set value $\dot{\gamma}_{r}$ of the control system of the ceramic mixture shear rate. These problems can be solved by applying the developed algorithm of the setting device, taking into account the subsequent stages of bricks production, and the observer of the ceramic mixture shear rate in the pressure head of the auger vacuum extruder [16].

\section{Discussion}

The proposed structural configuration of the control system is of great practical importance as it allows improving significantly the efficiency of the electrical engineering complex for shaping the ceramic mixture without substantial engineering changes in the structure of the auger vacuum extruder. However, the creation of the automatic control system of the electrical engineering complex for shaping the ceramic mixture should be preceded by solving a number of theoretical problems related to structural synthesis of the complex, which includes the electrical drives of the mixer, the auger, the vacuum pump, the belt 
feeder and the solenoid valve for water dosing, the algorithm design for effective control of these drives, creation of the new mathematical model of the ceramic mixture shaping in the auger vacuum extruder, synthesis of the generator of reference signals vector' algorithm of the ACS complex, adaptive to nonstationarity of making the ceramic mixture as well as to changing conditions of producing bricks of the limited number of brands.

\section{Conclusions}

A new control system configuration of the electrical engineering complex for shaping the ceramic mixture with the generator of reference signals vector has been developed. In order to solve the complicated problem of stabilizing the bricks strength under the conditions of reducing energy consumption in this system it has been offered to coordinate the control of the belt feeder, the mixer, the vacuum pump and the extruder drives, as well as the solenoid valve for water dosing.

The necessity of controlling the complex as a function of its shear rate in the exit section of the pressure head has been shown, as there exists no measuring device for its determination. Therefore, it is necessary to use the digital observer.

\section{References}

1. F. Handle, Extrusion in Ceramics (Springer, Berlin, 2007)

2. N.N. Evstratova, A.V. Rud, Design of auger extruders for shaping clay bricks (TNT, Stary Oskol, 2013)

3. V.S. Bogdanov, S.B. Bulgakov, A.S. Ilyin, Technological complexes and mechanical equipment in construction industry (Prospekt nauki, Saint Petersburg, 2010)

4. T. Kloft, Building material 4, 64-65 (2010)

5. V.Ya. Tolkachev, Technology of high-quality extrusion of products made of clay (Computer technologies, Krasnoyarsk, 2009)

6. S.Ya. Galitskov, M.A. Nazarov, K.S. Galitskov, International Journal of Applied Engineering 10-20, 40846-40852 (2015)

7. S.Ya. Galitskov, M.A. Nazarov, K.S. Galitskov, MATEC Web of Conferences 86, 1-6 (2016) doi: 10.1051/matecconf/20168604010

8. S.V. Zubanov, E.V. Tkachev, Urban Construction and Architecture 3(11), 90-96 (2013) doi: 10.17673/Vestnik.2013.03.18

9. O.A. Luneva, E.V. Averyanova, Urban Construction and Architecture 3(11), 70-72 (2013) doi: 10.17673/Vestnik.2013.03.14

10. W. Leisenberg, Zigelindustrie International 8, 25-32 (2000)

11. Yu.G. Barabanshchikov, PhD Thesis (St. Petersburg, 2006)

12. Yu.G. Barabanshchikov, Scientific and technical journal of SPBSPU 6-1, 170-175 (2006)

13. V.N. Mitroshin, Problems of control and simulation in complex systems: $18^{\text {th }}$ International Conference proceedings, 333-339 (Ofort, Samara, 2016)

14. E.Ya. Rapoport, Yu.E. Pleshivtseva, A.N. Diligenskaya, Problems of control and simulation in complex systems: 18th International Conference proceedings, 317-324 (Ofort, Samara, 2016)

15. J.E. Normey-Rico, E.F. Camacho. Control of dead-time processes (London, Springer, 2007).

16. S.Ya. Galitskov, K.S. Galitskov, M.A. Nazarov, Industrial and civil engineering, 9, 27-30 (2015). 